\title{
Fullerene Nanowires Produced by Single Particle Nanofabrication Technique and Their Photovoltaic Applications
}

\author{
Shotaro Suwa ${ }^{\mathrm{a}}$, Yuta Maeyoshi ${ }^{\mathrm{a}}$, Satoshi Tsukuda ${ }^{\mathrm{b}}$, Masaki Sugimoto \\ Akinori Saeki ${ }^{\text {a,d,** }}$ and Shu Seki ${ }^{\text {a,* }}$ \\ ${ }^{\text {a }}$ Department of Applied Chemistry, Graduate School of Engineering, \\ Osaka University, Osaka 565-0871, Japan \\ ${ }^{\mathrm{b}}$ Institute of Multidisciplinary Research for Advanced Materials, Tohoku University, 2-1-1, Katahira, \\ Aoba-ku, Sendai 980-8577, Japan. \\ ${ }^{\mathrm{c}}$ Takasaki Advanced Radiation Research Institute, Japan Atomic Energy Agency, 1233 Watanuki-machi, \\ Takasaki, Gunma 370-1292, Japan. \\ d PRESTO-JST, 4-1-8 Honcho Kawaguchi, Saitama 332-0012, Japan.
}

\begin{abstract}
The single particle nanofabrication technique (SPNT) provides a facile and universal method to afford homogeneous, stiff, and semiconducting nanowires composed of fullerene derivatives. Following our previous success in methanofullerene (PCBM) nanowires hybridized with bulk heterojunction organic photovoltaics (OPV) of poly(3-hexylthiophene) (P3HT) and PCBM, we extended the research to indene $\mathrm{C}_{60}$ bis-adduct (ICBA). The power conversion efficiency of P3HT:ICBA OPV incorporating optimized length of ICBA nanowires was improved from $2.36 \%$ to $2.92 \%$, alongside the increase of short circuit current density. We also discuss the interaction between substrate and unexposed fullerenes by examining immersing time to isolate such a short $(50 \mathrm{~nm})$ and thin (11 $\mathrm{nm}$ in radius) ICB A nanowire.
\end{abstract}

keywords: fullerene nanowire, single particle nanofabrication technique, organic photovoltaics

\section{Introduction}

Since the intriguing electronic features have been observed in the efficient electron transfer from $\pi$-conjugated polymer to fullerene, ${ }^{1,2)}$ research on organic photovoltaics (OPV) of this framework has been the focus of great attention with the aim at providing flexible and low-cost light-harvesting devices. ${ }^{3-6)}$ Bulk heterojunction (BHJ) OPV consisting of p-type conjugated polymer and n-type soluble fullerene is a simple but striking architecture for raising power conversion efficiency (PCE) by virtue of its bi-continuous interpenetrating network with a large $\mathrm{p} / \mathrm{n}$ interfaces. ${ }^{7)}$ The underlying requirement for a high PCE is the formation of optimal BHJ, and therefore the deterioration of BHJ motif during a long-term operation impairs the PCE ${ }^{8)}$ which must be addressed for the practical applications.

To this end, efforts have been devoted to the improvement of durability by thermal conversion from soluble to insoluble molecules, ${ }^{9)}$ photo-crosslinking reaction, ${ }^{10), 11)}$ addition of surfactant diblock polymer, ${ }^{12)}$ and thermodynamically-stable self-organized scaffold. ${ }^{13)}$ Besides, incorporation of robust and well-defined organic nanowires (e.g. $\mathrm{P} 3 \mathrm{HT},{ }^{14)}$ tetracene derivative, ${ }^{15)}$ phthalocyanyne ${ }^{16)}$ ) and inorganic ones (e.g. $\mathrm{CdSe},{ }^{17)} \mathrm{Ag}^{18)}$ ) into OPV has been explored for securing the efficient transport pathway of charge carriers, ${ }^{14-17)}$ sensitization, ${ }^{16)}$ transparent electrodes, ${ }^{18)}$ and enhancement of optical absorption by scattering ${ }^{19)}$ or grating ${ }^{20)}$ the incident sunlight.

Recently, we have reported the fabrication of fullerene nanowires ${ }^{21}$ by the single particle nanofabrication technique (SPNT) $)^{22,23)}$ and demonstrated its universal applicability to the wide range of fullerene derivatives. Along the individual trajectory of high-energy charged particle, 1-dimensional (1D) polymerization reaction is induced within the nanometer-scale cylindrical region. The 1D nanowires, visualized clearly after the development process, revealed their homogeneous density, radius, and length, which can be controlled easily by changing the fluence, energy (or molecular weight), and film

$\begin{array}{llr}\text { Received } & \text { April } & 4,2013 \\ \text { Accepted } & \text { May } & 10,2013\end{array}$


thickness, respectively (Figure 1(a)). ${ }^{21 \sim 23)}$ The hybridization of $[6,6]$-phenyl- $\mathrm{C}_{61}$-butyric acid methyl ester (PCBM) nanowires with typical BHJ of regioregular poly(3-hexylthiophene) (P3HT, Figure 1(b)) and PCBM led to a 7\% increase in PCE from 2.73 to $2.91 \%$ in the inverted cells with optimized density and length of nanowires. ${ }^{21)}$

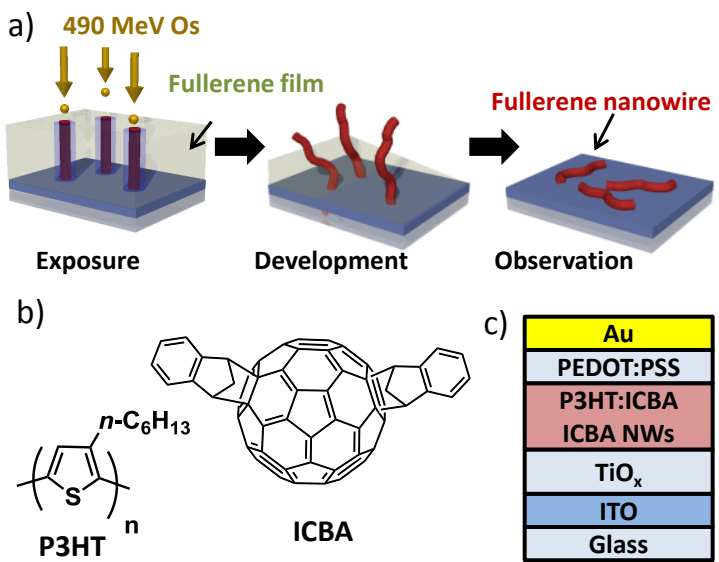

Figure 1. (a) Schematic illustration of fabrication of fullerene nanowires. (b) Chemical structures of P3HT and ICBA. (c) Inverted cell structure of OPV.

Herein we extend this fullerene nanowirehybridized $\mathrm{BHJ}$ to indene- $\mathrm{C}_{60}$ bis adducts (ICBA, Figure 1(b)), ${ }^{24)}$ which possesses the higher lowest unoccupied molecular orbital (LUMO) than PCBM. Accordingly the high open circuit voltage $\left(V_{\text {oc }}\right)$ has been realized in combination with P3HT. ${ }^{24), 25)}$ An inverted cell structure where ICBA nanowires are formed on the bottom cathode buffer layer $\left(\mathrm{TiO}_{\mathrm{x}}\right)$ is employed and we extensively survey the impact of nanowire length on the device performance.

\section{Experimental}

ICBA (purity >99\%), purchase from Frontier Carbon Inc. was dissolved in chlorobenzene (CB) and spin-cast on cleaned Si wafer. Film thickness was measured using a stylus surface profiler (Ulvac, Dektak 150). The films were irradiated using $490 \mathrm{MeV}$ Os particles from the cyclotron accelerator at the Takasaki Advanced Radiation Research Institute (TIARA) of the Japan Atomic Energy Agency. The irradiated ICBA films were developed in $\mathrm{CB}$ for $10 \mathrm{~min}$. The size and shape of the nanowires were observed by atomic force microscopy (AFM; Seiko Instruments Inc., Nanocute OP and Nanonavi II).

Poly(3-hexylthiophene) (P3HT; >98\% headto-tail regioregularity, $99.995 \%$ trace metals basis, $\left.M_{\mathrm{n}}=3-6 \times 10^{4} \mathrm{~g} \mathrm{~mol}^{-1}, M_{\mathrm{w}} / M_{\mathrm{n}}<2.5\right)$ was purchased from Aldrich. Solvents were purchased from Kishida Kagaku Corp. and were used as-received without further purification. PEDOT:PSS (Baytron P VP AI 4083) and ITO-coated glass substrates $\left(<15 \Omega\right.$ square $\left.^{-1}\right)$ were purchased from H. C. Stark and Sanyo Shinku Corp., respectively. The ITO glass substrates were successively cleaned in tetrahydrofuran, detergent, de-ionized water, acetone, and isopropyl alcohol for $10 \mathrm{~min}$ each with ultrasonication. The dried ITO glass substrates were subjected to UV-ozone treatment.

The $\mathrm{TiO}_{\mathrm{x}}$ precursor (Koujundo Kagaku Corp.) was cast on the ITO layer by spin-coating after passing through a $0.2 \mu \mathrm{m}$ filter. ${ }^{21)}$ The layers were annealed on a hot plate at $150{ }^{\circ} \mathrm{C}$ for $10 \mathrm{~min}$. A $2 \mathrm{wt} \%$ chloroform solution of ICBA was cast onto the $\mathrm{TiO}_{\mathrm{x}}$ layer in a nitrogen glove box by spin-coating after passing through a $0.2 \mu \mathrm{m}$ filter. The films were irradiated with $490 \mathrm{MeV}$ Os particles, developed with $\mathrm{CB}$, and the P3HT:ICBA active layer was cast by spin-coating of $o$-dichlorobenzene solution and annealed in a glove box. An aqueous solution of poly(3,4-ethylenedioxythiophene):poly(styrenesulfonate) (PEDOT:PSS) with 1 wt $\%$ poly (ethylene)glycol as a surfactant was dropped onto the active layer after passing through a $0.2 \mu \mathrm{m}$ filter and immediately spin-coated. The layers were annealed on a hot plate at $150{ }^{\circ} \mathrm{C}$ for $10 \mathrm{~min}$. The anode consisted of a $50 \mathrm{~nm}$ Au layer was deposited through a shadow mask on top of the active layers by thermal evaporation in a vacuum chamber. The resulting device configuration as shown in Figure 1(c) was ITO $(120-160 \mathrm{~nm}) / \mathrm{TiO}_{x}$ (ca. 10 nm)/active layer (ca. 220 $\mathrm{nm}) / \mathrm{PEDOT}$ :PSS $(50-100 \mathrm{~nm}) / \mathrm{Au}(50 \mathrm{~nm})$ with an active area of $7.1 \mathrm{~mm}^{2}$. Current-voltage $(J-V)$ curves were measured in the similar fashion with our report ${ }^{26)}$ by using a source-measure unit (ADCMT Corp., 6241A) under AM 1.5 G solar illumination at $100 \mathrm{~mW} \mathrm{~cm}$ (1 $^{-2}$ sun) using a 300 W solar simulator (SAN-EI Corp., XES-301S).

\section{Results and discussion}

AFM micrographs of ICBA nanowires formed on Si wafers are displayed in Figure 2(a). To avoid the spatial overlaps, the fluence of exposed ion beam was reduced to $2 \times 10^{8} \mathrm{~cm}^{-2}$, one fifth of that used in the nanowire-hybridized OPV. The length of the nanowires, corresponding perfectly to the original film thickness, ${ }^{21)}$ is increased straightforward from ca. 50 to $200 \mathrm{~nm}$, highlighting the rigid and stiff nature of the fullerene nanowires in sharp contrast to the soft and flexible nanowires made of synthetic polymers. ${ }^{27)}$ 29) The radius of ICBA nanowires was reported to be $10.9 \pm 1.1 \mathrm{~nm},{ }^{21)}$ slightly larger than bare $\mathrm{C}_{60}(7.9 \pm 1.0 \mathrm{~nm})$ and PCBM $(8.6 \pm 0.8 \mathrm{~nm})$, suggestive of the correlation 

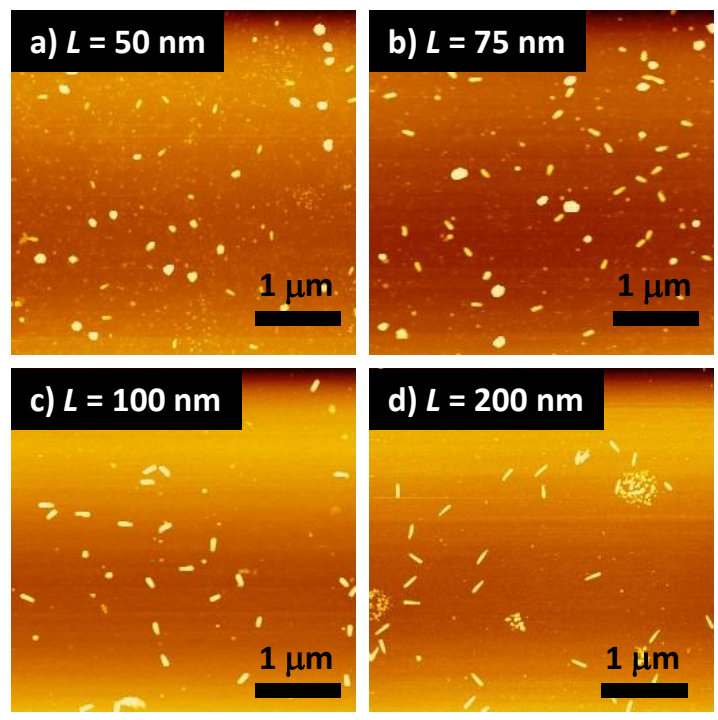

\section{e) $L=50 \mathrm{~nm}$ \\ (30 min dev.)}

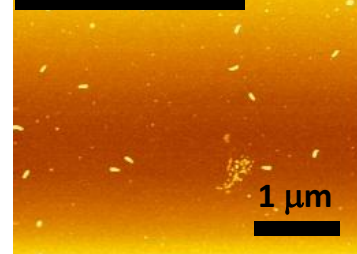

Figure 2. AFM height images of ICBA nanowires with the average lengths of (a) 50, (b) 75, (c) 100, and (d) $100 \mathrm{~nm}$ on Si wafers after $10 \mathrm{~min}$ development in chlorobenzene. The ion beam fluence was $2 \times 10^{8} \mathrm{~cm}^{-2}$. (e) AFM images of (a) after extra 30 min development.

between the density of the fullerene film and the nanowire radius. Because ICBA, bulky indene bis-adduct of fullerene, is a mixture of stereoisomers which ensures the solubility in organic solvents by preventing the excessive crystallization, the film would have looser packing than mono-adduct PCBM and bare $\mathrm{C}_{60}$.

Another important aspect of fullerene nanowires is its extremely high cross-linking efficiency. The $G$ value, defined by the number of chemical reactions per $100 \mathrm{eV}$ absorbed energy used in radiation chemistry, is as large as $55(100$ $\mathrm{eV})^{-1},{ }^{21)}$ more than two orders of magnitude higher than those of polymers $(0.1 \sim 1$ (100 $\left.(\mathrm{eV})^{-1}\right),{ }^{30)}$ and even higher than the initial ionization yield (ca. $\left.\left.5(100 \mathrm{eV})^{-1}\right)\right)^{31)}$ This is indicative of a chain polymerization reaction of presumed $[2+2]$ cycloaddition $^{31)}$ mediated by reactive intermediates produced via ionization.

By comparing the morphologies of the nanowires of different lengths, one might notice that large island-like features exit in Figures 2(a) and 2(b) (50 and $75 \mathrm{~nm}$ in length), while such structures disappear for the longer nanowires as shown in Figures 2(c) and 2(d) (100 and $200 \mathrm{~nm}$ in length). This island-like feature exhibited a hemispherical shape with the height of around 30 $\sim 60 \mathrm{~nm}$ and the radius of ca. $100 \mathrm{~nm}$, which does not coincide with the scale of fullerene nanowires. The bundling of nanowires during the short development process (ca. $10 \mathrm{~min}$ ) is not plausible, because the terminal of the nanowire is covalently connected to the $\mathrm{Si}$ wafer and the density of the nanowires is always equivalent to the fluence. Furthermore, the number density of hemispherical structures on an unit area was almost identical to the number of incident particles, suggesting again small contribution of bundling of nanowires which leads to considerable decrease in the number density of structure via aggregation. One possible explanation is that the strong aggregating nature of fullerenes ${ }^{33), 34)}$ onto both the latent image of nanowires and substrate does not allow dissolving during the short development time. In the case of long nanowires (> $100 \mathrm{~nm}$ ), unexposed fullerenes on the surface of thick film are easy to be developed, due to the negligible interaction with the substrate. Subsequently the solvent molecules are able to penetrate into the deep area assisted by effective solvation and exchange of fresh solvent molecules. To clarify this expectation, we kept the $50 \mathrm{~nm}$-length nanowires (Figure 2(a)) in chlorobenzene for extra $30 \mathrm{~min}$. The AFM image after the long development process is shown in Figure 2(e). The island-like structures are not observed anymore and the short nanowires are clearly resolved. Therefore we conclude that short nanowires (i.e. thin film) need a long development time because of the non-negligible interaction between the substrate and fullerenes. Based on the observed length of the ICBA nanowires, the aspect ratios of nanowires are determined as 4.6 to 18.3 with negligibly small distribution. The ratio seems to be high enough as realized by conventional miniaturization of organic materials, however feasibility of SPNT has been demonstrated to achieve 1D-nanowires with ultra-high aspect ratio. ${ }^{35), 36)}$ This is the case giving uniform distribution of nanowire length with negligibly small distribution.

BHJ-type OPVs of P3HT:ICBA were fabricated by incorporating ICBA nanowires with different lengths. The thin ICBA films on $\mathrm{TiO}_{\mathrm{x}} / \mathrm{ITO} /$ glass were exposed to $490 \mathrm{MeV}$ Os ions at the fluence of $10^{9} \mathrm{~cm}^{-2}$ and developed in chlorobenzene. This fluence was chosen on the basis of the successful example of P3HT:PCBM. ${ }^{21)}$ The P3HT:ICBA $(1: 1 \mathrm{w} / \mathrm{w} \%)$ and PEDOT:PSS layers were subsequently spin-coated, annealed, and $\mathrm{Au}$ anode was thermally deposited in a vacuum chamber. 
The current density $(J)$-voltage $(\mathrm{V})$ curves of these inverted cells under illumination from an AM 1.5 G solar simulator are shown in Figure 3(a). The PCE, short circuit current density $\left(J_{\mathrm{sc}}\right)$, $V_{\mathrm{oc}}$, and fill factor (FF) are plotted in Figures 3(b) and $3(\mathrm{c})$, as a function of nanowire length $(L)$. The $L=0 \mathrm{~nm}$ corresponds to the device without ICBA nanowires, but it was immersed in chlorobenzene prior to casting the active layer in the similar fashion with the hybridized devices. The PCE underwent 23\% enhancement from 2.36
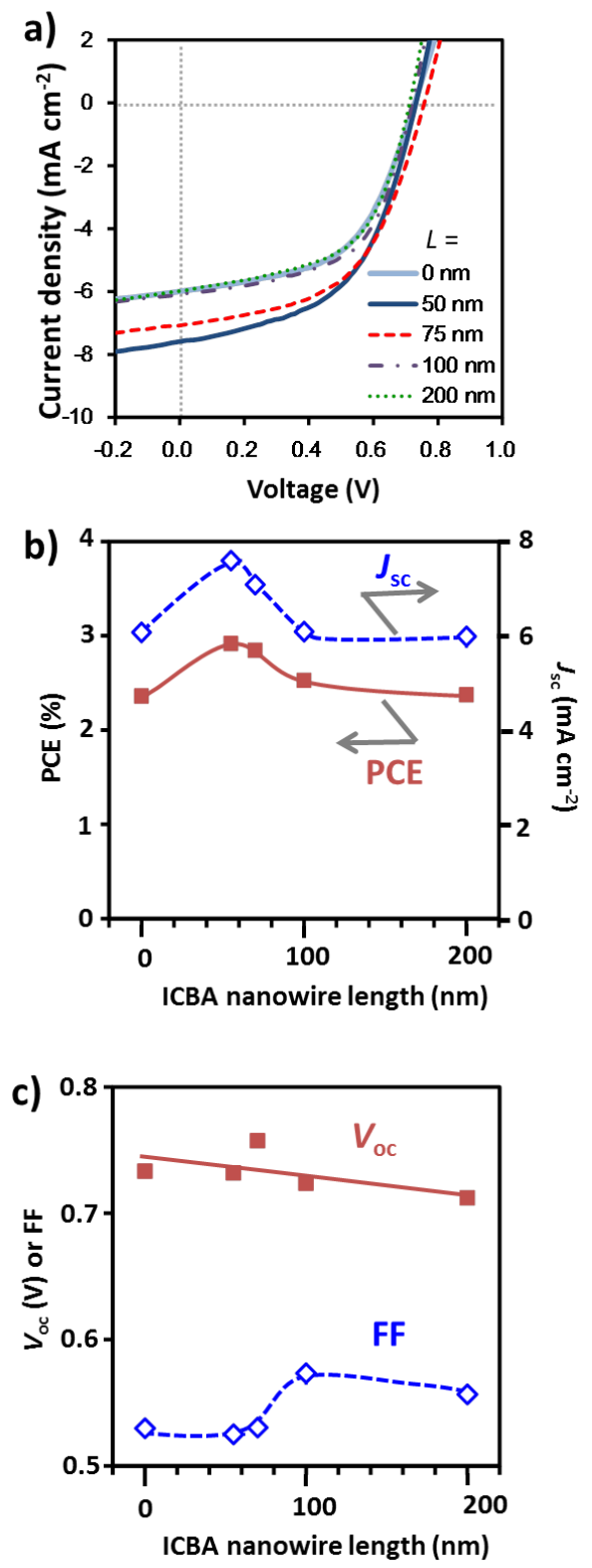

Figure 3. (a) $J-V$ curves of P3HT:ICBA (1:1 w/w) hybridized with ICBA nanowires $\left(1 \times 10^{9} \mathrm{~cm}^{-2}\right)$ under AM $1.5 \mathrm{G}$ (1 sun). $L$ denotes the nanowire length. (b) PCE and $J_{\mathrm{sc}}$ vs. nanowire length. (c) $V_{\mathrm{oc}}$ and FF vs. nanowire length.

to $2.92 \%$ by incorporating $50 \mathrm{~nm}$-length ICBA nanowires, mainly ascribed to the increase in $J_{\mathrm{sc}}$
( 6.07 to $7.59 \mathrm{~mA} \mathrm{~cm}^{-2}$ ). The favorable vertical segregation of n-type ICBA nanowires on the bottom cathode is assumed responsible for this improvement, being line with the previous reports on the effect of post-annealing. ${ }^{37)}$ The $V_{\text {oc }}(\sim 0.73$ V) and FF (0.53) are not affected so much for the short nanowires $(<75 \mathrm{~nm})$, and thus the PCEs of 50 and $75 \mathrm{~nm}$ nanowires were almost identical (2.92 and $2.84 \%$, respectively). These results look exactly like what we observed in OPV of PCBM nanowires-hybridized P3HT:PCBM, ${ }^{21)}$ although the optimized length of nanowires became half of the PCBM case (ca. $120 \mathrm{~nm}$ ). The observed $V_{\mathrm{oc}}$ is, however, lower than that of well-optimized normal cell of P3HT:ICBA without nanowires $\left.(0.87 \mathrm{~V}),{ }^{24}\right)$ indicating that there are still margin of improvement by fine-tuning of processing condition. The presence of lengthy nanowires (> $200 \mathrm{~nm}$ ) turned to deteriorate the device performance, in good correspondence with the trend found in PCBM nanowires. ${ }^{21)}$ The $200 \mathrm{~nm}$ length is comparable with the active layer thickness (ca. $220 \mathrm{~nm}$ ), and thus ill-directed flow of charge carriers and/or trap at the electronically-damaged parts of nanowires might be involved, leading to the increase of charge recombination that cannot contribute the photocurrent.

The fullerene nanowires are thermally stable because of the covalent polymerization, as evident from the preservation of their structures ever after thermal annealing. ${ }^{21)}$ This could open up opportunities to create a versatile platform of not only electronic applications but also manipulators, ${ }^{29)}$ thereby widening the scope for potential application of this uniform, controllable, and semiconducting organic nanowires.

\section{Conclusion}

ICBA nanowires-hybridized P3HT:ICBA $(1: 1 \quad \mathrm{w} / \mathrm{w}) \quad$ OPVs were investigated, demonstrating 23\% improvement of PCE from $2.36 \%$ without nanowires to $2.92 \%$ by incorporating $50 \mathrm{~nm}$-length nanowires at the ion beam fluence of $10^{9} \mathrm{~cm}^{-2}$. The increase in $J_{\text {sc }}$ is the primary factor, which is thought arisen from the favorable vertical segregation of $n$-type ICBA nanowires on the bottom cathode of inverted cell. For the complete development of such short nanowires, more sufficient immersing time is necessary than that for the long nanowires, due to the relative increase of aggregating interaction between unexposed fullerene and substrate. The robust nature of the 1D fullerene nanowires offers plenty of room for further functionalization of their electronic and mechanical properties. 


\section{Acknowledgements}

This work was supported by JSPS Funding Program for Next-Generation World-Leading Researches (NEXT Program), by the Precursory Research for Embryonic Science and Technology (PRESTO) program of the Japan Science and Technology Agency (JST), by Grant-in-aid from Ogasawara Science and Technology Foundation, and by KAKENHI from MEXT, Japan.

\section{References}

1. N. S. Sariciftci, L. Smilowitz, A. J. Heeger, F. Wudl, Science 285 (1992) 1474.

2. S. Morita, A. A. Zakhidov, K. Yoshino, Solid State Commun. 82 (1992) 249.

3. G. Li, R. Zhu, Y. Yang, Nature Photo. 6 (2012) 153.

4. D. Credgington, J. R. Durrant, J. Phys. Chem. Lett. 3 (2012) 1465.

5. D. Gendron, M. Leclerc, Energy Environ. Sci. 4 (2011) 1225.

6. P. M. Beaujuge, J. M. J. Fréchet, J. Am. Chem. Soc. 133 (2011) 20009.

7. G. Yu, J. Gao, J, C. Hummelen, F. Wudl, A. J. Heeger, Science 270 (1995) 1789.

8. M. Jørgensen, Ki. Norrman, F. C. Krebs, Sol. Ener. Mater. Sol. Cells, 92 (2008) 686.

9. H. Tanaka, Y. Abe, Y. Matsuo, J. Kawai, I. Soga, Y. Sato, E. Nakamura, Adv. Mater. 24 (2012) 3521.

10. B. J. Kim, Y. Miyamoto, B. Ma, J. M. J. Fréchet, Adv. Funct. Mater. 19 (2009) 2273.

11. G. Griffini, J. D. Douglas, C. Piliego, T. W. Holcombe, S. Turri, J. M. J. Fréchet, J. L. Mynar, Adv. Mater. 23 (2011) 1660

12. J.-H. Tsai, Y.-C. Lai, T. Higashihara, C.-J. Lin, M. Ueda, W.-C. Chen, Macromolecules $\mathbf{4 3}$ (2010) 6085.

13. C. -L. Wang, W. -B. Zhang, H. -J. Sun, R. M. Van Horn, R. R. Kulkarni, C. -C. Tsai, C. -S. Hsu, B. Lotz, X. Gong, S. Z. D. Cheng, $A d v$. Energy Mater. 2 (2012) 1375.

14. J. S. Kim, J. H. Lee, J. H. Park, C. Shim, M. Sim, K. Cho, Adv. Funct. Mater. 21 (2011) 480.

15. T. Suzuki, T. Okamoto, A. Saeki, S. Seki, H. Sato, Y. Matsuo, ACS Appl. Mater. Interfaces 5 (2013) 1937.

16. S. M. Yoon, S. J. Lou, S. Loser, J. Smith, L. X. Chen, A. Facchetti, T. Marks, Nano Lett. 12 (2012) 6315.

17. M. Schierhorn, S. W. Boettcher, J. H. Peet, E. Matioli, G. C. Bazan, G. D. Stucky, M. Moskovits, ACS Nano 4 (2010) 6132.

18. C.-C. Chen, L. Dou, R. Zhu, C.-H. Chung, T.-B. Song, Y. B. Zheng, S. Hawks, G. Li, P. S.
Weiss, Y. Yang, ACS Nano 6, (2012) 7185.

19. X. Li, W. C. H. Choy, L. Huo, F. Xie, W. E. I. Sha, B. Ding, X. Guo, Y. Li, J. Hou, J. You, Y. Yang, Adv. Mater. 24 (2012) 3046.

20. D. H. Wang, K. H. Park, J. H. Seo, J. Seifter, J. H. Jeon, J. K. Kim, J. H. Park, O O. Park, A. J. Heeger, Adv. Energy Mater. 1 (2011) 766.

21. Y. Maeyoshi, A. Saeki, S. Suwa, M. Omichi, H. Marui, A. Asano, S. Tsukuda, M. Sugimoto, A. Kishimura, K. Kataoka, S. Seki, Sci. Rep. 2 (2012) 600.

22. S. Seki, K. Maeda, S. Tagawa, H. Kudoh, M. Sugimoto, Y. Morita, H. Shibata, Adv. Mater. 13 (2001) 1663.

23. S. Seki, S. Tsukuda, K. Maeda, Y. Matsui, A. Saeki, S. Tagawa, Phys. Rev. B 70 (2004) 144203.

24. G. Zhao, Y. He, Y. Li, Adv. Mater. 22 (2010) 4355.

25. X. Guo, C. Cui, M. Zhang, L. Huo, Y. Huang, J. Hou, Y. Li, Energy Environ. Sci., 5 (2012) 7943.

26. A. Saeki, M. Tsuji, S. Seki, Adv. Energy Mater. 1 (2011) 661.

27. S. Tsukuda, S. Seki, M. Sugimoto, S. Tagawa, J. Phys. Chem. B 110 (2006) 19319.

28. S. Seki, A. Saeki, W. Choi, Y. Maeyoshi, M. Omichi, A. Asano, K. Enomoto, C. Vijayakumar, M. Sugimoto, S. Tsukuda, and S.-i. Tanaka, J. Phys. Chem. B 116 (2012) 12857.

29. M. Omichi, H. Marui, K. Takano, S. Tsukuda, M. Sugimoto, S. Kuwabata, S. Seki, ACS Appl. Mater. Interfaces 4 (2012) 5492.

30. W. Burlant, J. Neerman, V. Serment, J. Polym. Sci. 58 (1962) 491.

31. Y. Hatano, Y. Katsumura, A. Mozumder, in Charged Particle and Photon Interactions with Matter, -Recent Advances, Applications, and Interfaces; CRS Press (2011).

32. P. Zhou, Z. -H. Dong, A. M. Rao, P. C. Eklund. Chem. Phys. Lett. 211 (1993) 337.

33. K. L. Chen, M. Elimelech, Langmuir 22 (2006) 10994.

34. S. S. Babu, H. Mohwald, T. Nakanishi, Chem. Soc. Rev. 39 (2010) 4021.

35. A. Asano, Y. Maeyoshi, K. Takano, M. Omichi, M. Sugimoto, M. Yoshikawa, S. Tsukuda, S. Tanaka, A. Saeki, S. Seki, J. Photopolym. Sci. Technol., 25 (2012) 685.

36. S. Seki, S. Watanabe, M. Sugimoto, S. Tagawa, S. Tsukuda J. Photopolym. Sci. Technol., 21 (2008) 541.

37. A. Orimo, K. Masuda, S. Honda, H. Benten, S. Ito, H. Ohkita, H. Tsuji, Appl. Phys. Lett. 96 (2010) 043305. 